\title{
Fire and post-fire performance of circular steel tube confined reinforced concrete columns
}

\author{
F. Liu ${ }^{\mathrm{a}, \mathrm{b} *}$, H. Yang ${ }^{\mathrm{a}, \mathrm{b}}$, and S. Zhang ${ }^{\mathrm{a}, \mathrm{b}}$ \\ a Key Lab of Structures Dynamic Behavior and Control (Harbin Institute of Technology), Ministry of \\ Education, Heilongjiang, Harbin, 150090, PR China \\ ${ }^{\mathrm{b}}$ Key Lab of Smart Prevention and Mitigation of Civil Engineering Disasters of the Ministry of Industry and \\ Information Technology, Harbin Institute of Technology, Harbin, 150090, China \\ *corresponding author, e-mail address: fqliu@hit.edu.cn
}

\begin{abstract}
Fire and post-fire behaviours of reinforced concrete columns confined by circular steel tubes, also known as circular steel tube confined reinforced concrete (STCRC) columns, are investigated in this paper. 5 full-scale specimens exposed to fire and 47 specimens after fire exposure were tested. Temperatures across the sections, displacement versus time curves, fire resistance, load versus displacement responses and load-bearing capacities were measured and discussed. A finite element (FE) model was developed using the program ABAQUS, and validated against the test results from the present study. Simplified design methods were proposed for predicting the fire resistance and residual load-bearing capacity of the STCRC columns under and after fire exposure, respectively.
\end{abstract}

Keywords: circular steel tube confined reinforced concrete; experiments; simulation; temperature; fire; fire resistance; post-fire; residual load-bearing capacity.

\section{Introduction}

The steel tube confined reinforced concrete (STCRC) column is a composite member with outer steel tube mainly working as hoop reinforcement. Steel tube in STCRC columns is terminated at beam to column connections (as shown in Fig.1), therefore no load is directly applied on the steel tube and the possibility of local buckling in steel tube is reduced. The confinement effect in STCRC columns begins from the onset of loading and can be maximized, which significantly enhances the concrete strength and ductility. Owning to the discontinuity of steel tube, the STCRC column to reinforced concrete beam connections can be designed and constructed following methods for conventional reinforced concrete structures, which avoids complexities of connections of concrete-filled steel tubular columns to reinforced concrete beams.

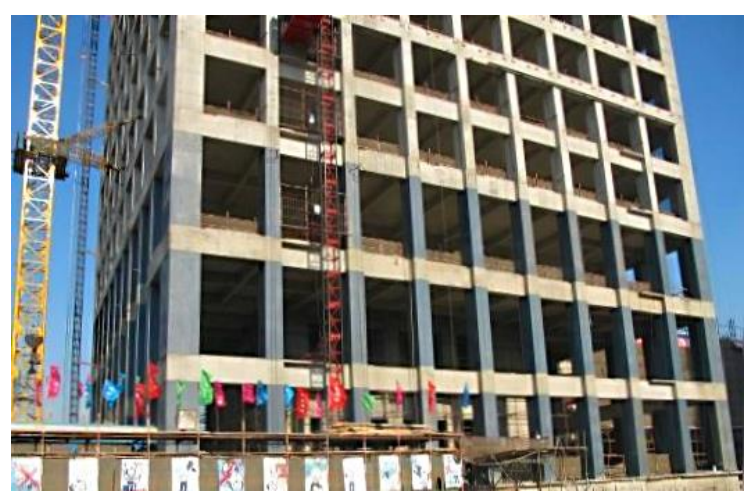

Fig. 1. A buildings using STCRC columns in the bottom three stories [1]

The STCRC column was firstly proposed by Tommi et al. [2-4], in order to prevent shear failure and improve the ductility of the stub columns in reinforced concrete structures. After that, extensive studies have been performed on the compression behaviour and seismic performance of the STCRC column at ambient temperature by Aboutaha et al. [5, 6], Sun et al. $[7,8]$, Han et al. [9,10], Liu et al. [1,11-14] and Yu et al. [15].

However, there is no reported research on the STCRC column related to elevated 
temperatures. In order to disclose behaviours of the STCRC columns at and after elevated temperatures, experiments and numerical analysis were conducted herein. Experiments were carried out to identify fundamental behaviours of these columns under and after fire exposure. A finite element (FE) model, adopting sequentially coupled thermal-stress analysis, was developed using the software ABAQUS and validated against test results. Parametric studies were performed to identify influences of these key parameters on behaviours of STCRC columns under fire and after fire. Design methods for predicting fire resistance and residual capacities were proposed, which can be used for fire safety design and damage evaluation of the STCRC columns, respectively.

\section{Experimental studies}

\subsection{Specimens tested at high temperatures}

Five full-scale specimens, including four STCRC columns and one concrete-filled steel tubular (CFST) column, were tested to failure under the ISO 834 standard fire. All of these columns have a diameter of $300 \mathrm{~mm}$ and a length of $3.81 \mathrm{~m}$. Load ratio and mode of specimens (mode a and mode b) were considered. The steel tube exposed to fire is continuous for the specimens of mode a, as show in Fig.2(a). The steel tube exposed to fire was equally divided into three parts for mode $b$ (Fig.2(b)), in order to further decrease the possible vertical load beared by the steel tube due to the bond stress and friction between the steel tube and concrete.

Temperatures of the outer steel tube and inner concrete were measured during the test. Typical results are shown in Fig.3, in which $d$ is the distance between measured point to outer surface of steel tube. Measured temperature decreases from the outer steel tube to concrete center. There is a platform for the temperaturetime curve of concrete at about $100{ }^{\circ} \mathrm{C}$ due to moisture evaporation.

Axial deformations of specimens were monitored during the test. Typical results are shown in Fig.4. As observed, the axial deformation can be divided into expansion, stable contraction and rapid contraction. When axial deformation or deformation velocity exceeds limitations, the corresponding time is fire resistance.

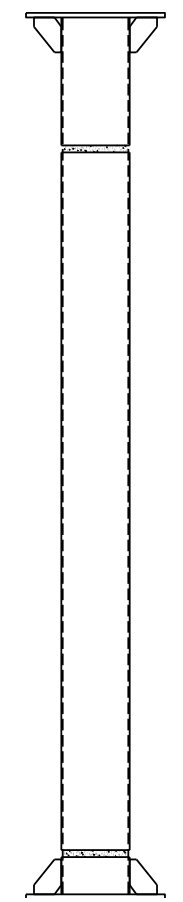

(a) mode a

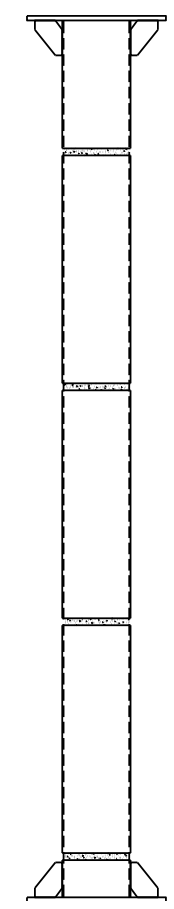

(b) mode b
Fig. 2. Schematic view of the specimen

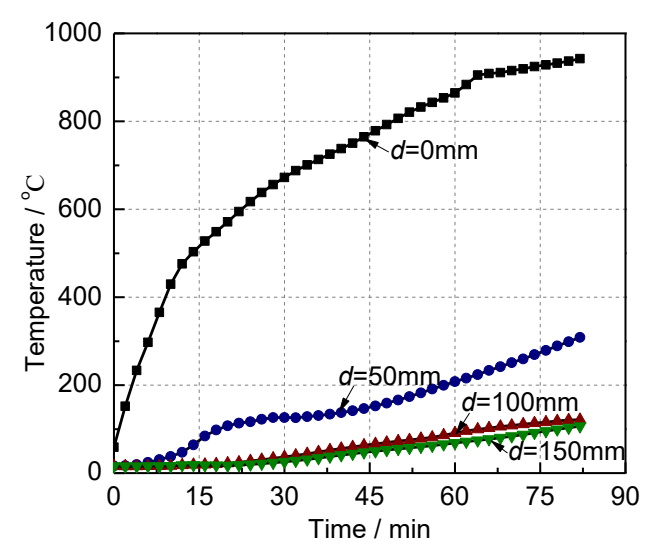

Fig. 3. Temperatures in the specimen

\subsection{Specimens tested after fire exposure}

A total of 47 circular STCRC columns after exposure to ISO 834 standard fire were tested, including 21 axially loaded stub columns [16], 12 eccentrically loaded stub columns [17] and 14 axially loaded slender columns [18]. The considered parameters were heating time $(0$, $30 \mathrm{~min}, 60 \mathrm{~min})$, length to diameter ratio $(3,6$, $10)$, concrete strength (C30, C50), cross section dimension $(200 \mathrm{~mm}, 250 \mathrm{~mm})$ and load eccentricity $(0,25 \mathrm{~mm}, 50 \mathrm{~mm})$. More details can be found in [16-18]. 


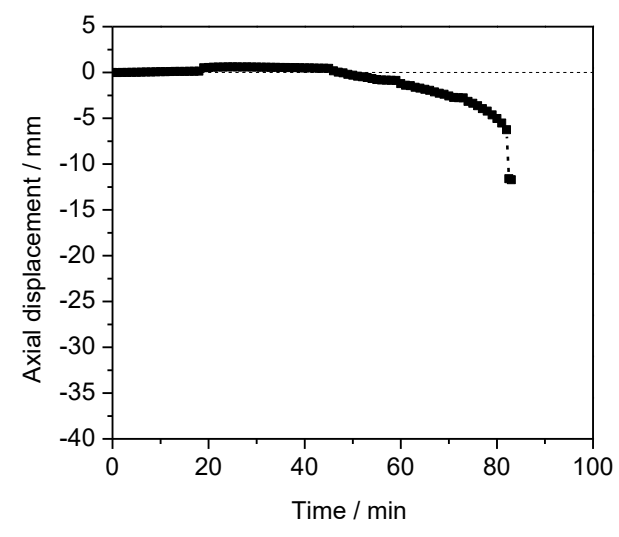

Fig. 4. Axial deformation-time curve of the specimen

The specimens were heated in an unstressed condition, which is considered to be more conservative than under load in terms of evaluating the residual strength of concrete after fire [19-22]. The ISO 834-1975 standard fire curve [23], including heating and cooling phases, were employed in this study. The heating time was taken as $30 \mathrm{~min}$ and $60 \mathrm{~min}$, corresponding cooling time (down to $200{ }^{\circ} \mathrm{C}$ ) was about $60 \mathrm{~min}$ and $90 \mathrm{~min}$, respectively. Therefore the total exposure time was $90 \mathrm{~min}$ and $150 \mathrm{~min}$, respectively. Cross section temperatures were monitored and recorded during the heating and cooling phases. After cooling to ambient temperatures, these specimens were loaded to failure. Loaddisplacement curves, strains of steel tube and failure modes were obtained.

The measured typical temperatures in specimens are shown in Fig.5, in which $d$ is the distance form measured point to outer surface of steel tube. The achieved maximum temperature decreases from the outer steel tube to concrete center, and the corresponding time increases. The delay of temperature rise in concrete can be attributed to the high thermal capacity of concrete and the protection provided by surrounding materials [16].

The measured typical load-displacement curves are illustrated in Fig.6. It can be found that the load-bearing capacity decreases with the increase of heating time. For specimens after heating $30 \mathrm{~min}$ and $60 \mathrm{~min}$, the corresponding load-bearing capacity decreases $11.3 \%$ and $22.5 \%$ respectively, relative to that of unexposed specimen.

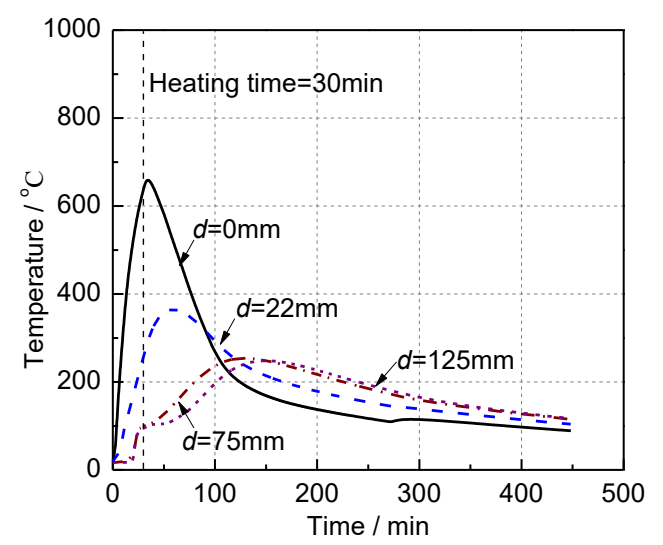

Fig. 5. Temperatures in the specimen during heating and cooling phases [16]

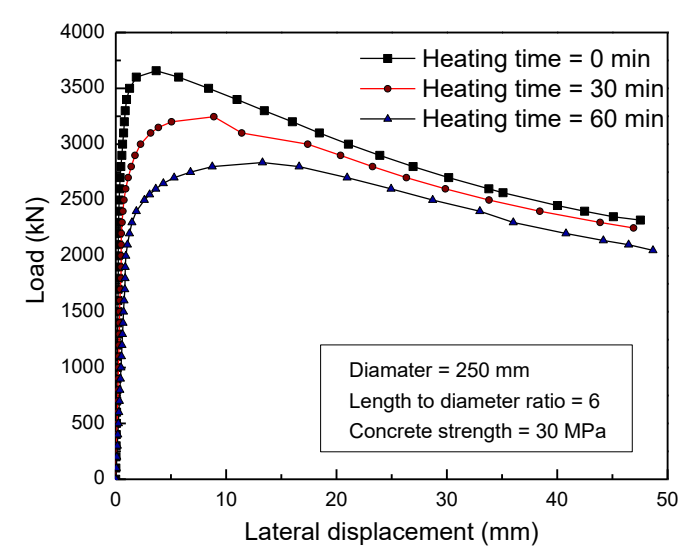

Fig. 6. Load-displacement curves [17]

Typical failure modes of specimens are shown in Fig.7. Axially loaded stub columns failed by shear failure, as shown in Fig.7(a). Concrete crushing occurred in eccentrically loaded stub columns, and local buckling was also observed in the compression side (Fig.7(b)). As expected, axially loaded slender columns failed by global buckling, as given in Fig.7(c).

\section{Numerical analysis}

A finite element (FE) model was developed using the sequentially coupled thermal-stress analysis method to investigate the fire and postfire performance of the circular STCRC columns. A finite element model of the circular STCRC is shown in Fig.8. Axial load was only applied on the core concrete in the simulation. Details of the finite element can be found in [24].

The developed finite element model was validated against circular STCRC columns tested in this study, reinforced concrete filled steel tubular columns tested by Chabot and Lie [25], Romero et al. [26], Han et al. [27]. 
Comparisons between predicted and test temperatures and deformations are shown in Fig.9 and Fig.10 respectively, which confirms the robustness of the finite element model.

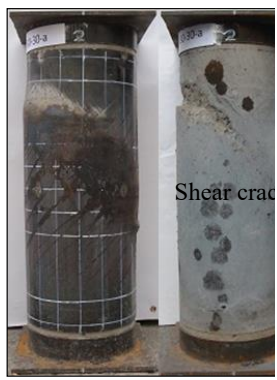

(a) axially loaded stub

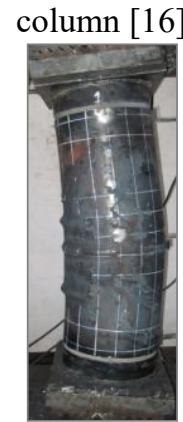

(b) eccentrically loaded stub column [17]

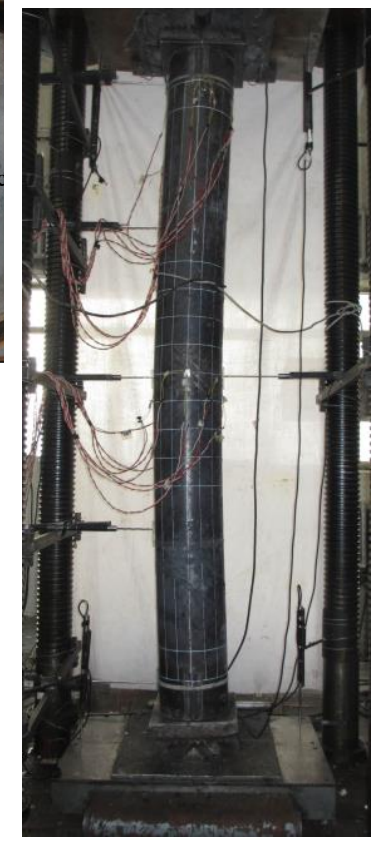

(c) axially loaded slender column [18]
Fig. 7. Typical failure modes
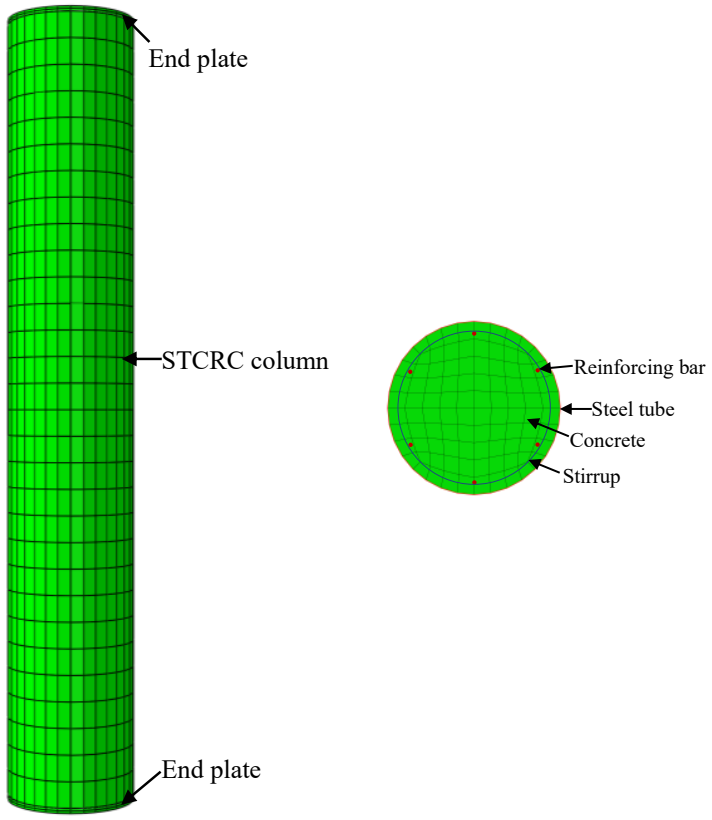

(a) Schematic view study results are not presented herein for the limited paper length.

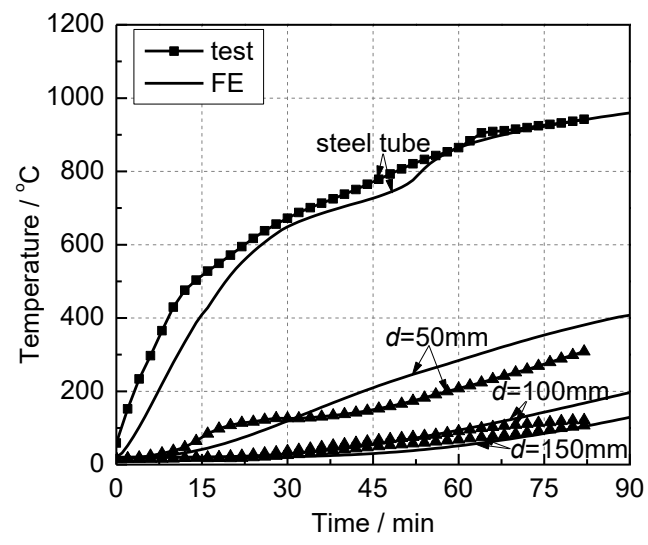

(a) STCRC column

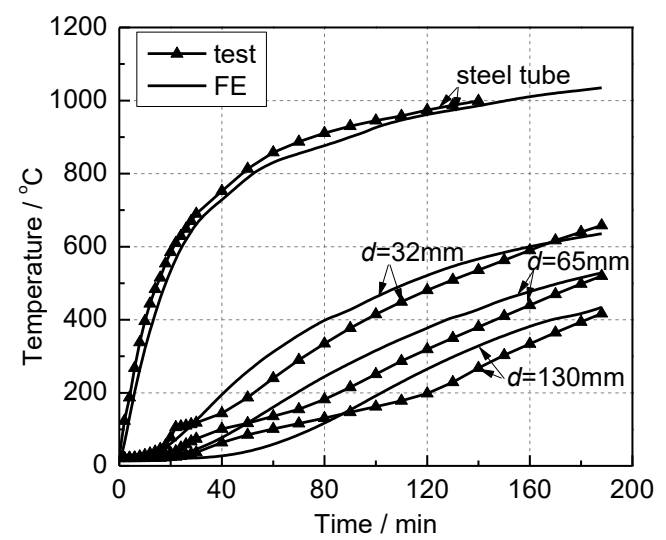

(b) Reinforced concrete filled steel tubular column

Fig. 9. Comparisons between predicted and test temperatures

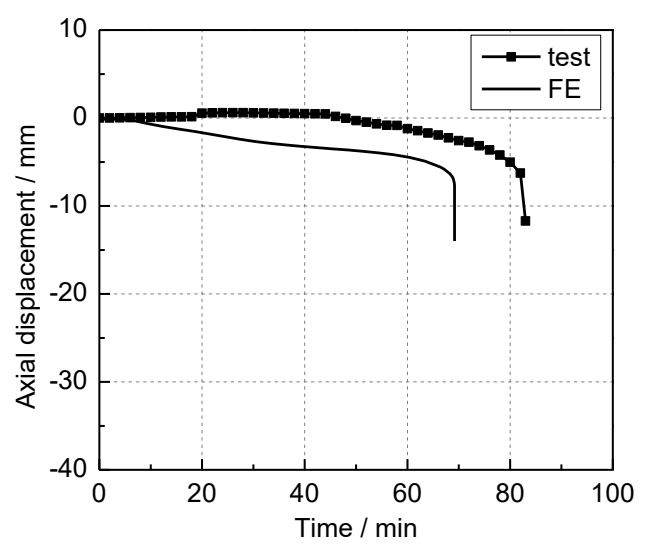

(a) STCRC column

Fig. 8. FE model of STCRC columns [17]

The finite element model was then employed to conducted parametric studies to investigate influences of key parameters on the fire resistance or residual load-bearing capacities of the STCRC columns. Parametric 


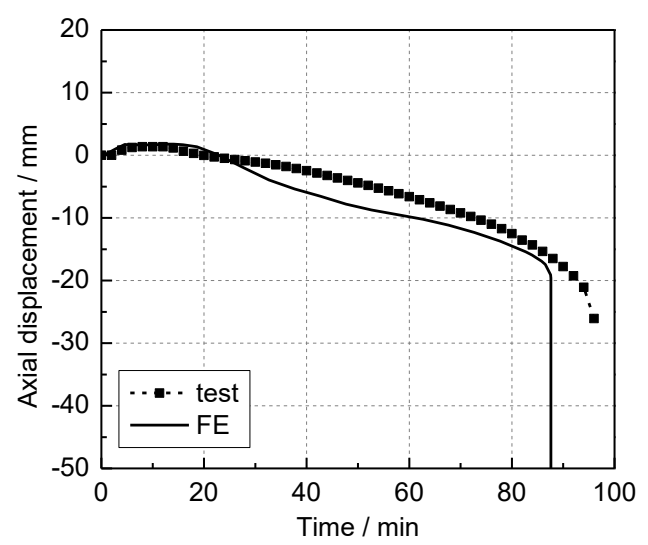

(b) Reinforced concrete filled steel tubular column

Fig. 10. Comparisons between predicted and test deformations

\section{Design method}

Liu and Zhou [11] proposed a design method for predicting the cross-sectional capacity of the STCRC columns at ambient temperature, which has been adopted by Chinese code "Technical code for tubed concrete structures". Consistent with this method, design methods for predicting loadbearing capacity of circular STCRC columns under and after fire exposure were proposed respectively by introducing influences of elevated temperatures.

Details of the method predicting loadbearing capacity of circular STCRC columns exposed to fire can be found in [24]. The loadbearing capacity under fire decreases with increasing time. When it equals to the applied axial load, corresponding time is fire resistance. Comparisons between predicted and test fire resistance is shown in Fig.11. The design method for predicting residual load-bearing capacity of the circular STCRC columns can be found in [16-18]. Comparisons between predicted and test load-bearing capacities of the circular STCRC columns are illustrated in Fig.12. As observed from Fig.11 and Fig.12, the proposed design methods can yield good predictions of the fire resistance and residual load-bearing capacity of the circular STCRC columns under fire and after fire exposure, respectively.

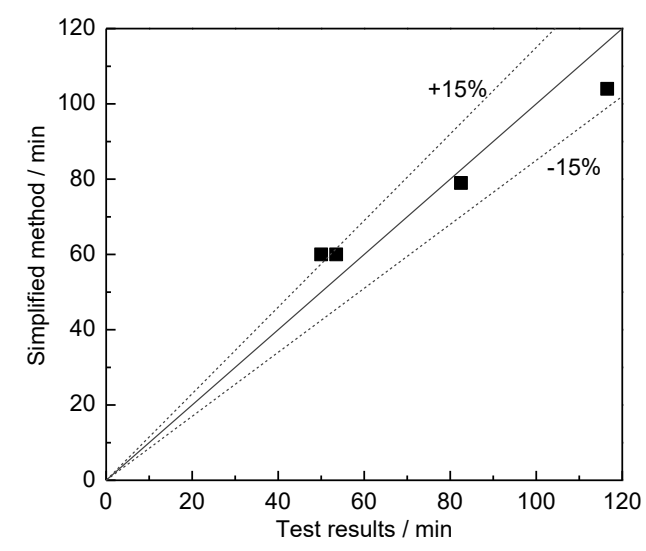

Fig. 11. Comparisons between predicted and test fire resistance

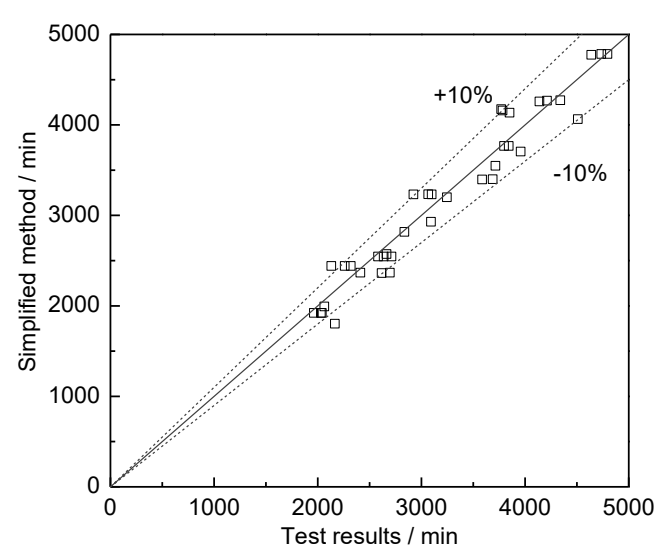

Fig. 12. Comparisons between predicted and test residual capacities

\section{Conclusions}

Fire and post-fire performance of circular steel tube confined reinforced concrete columns were investigated experimentally and numerically in this study. Fundamental behaviours of these columns were disclosed, and simplified design methods were proposed, which may be helpful for fire safety design and post-fire evaluation of the circular steel tube confined reinforced concrete columns.

\section{Acknowledgements}

The research presented in this paper was sponsored by the National Natural Science Foundation (No. 51508131), the Fundamental Research Funds for the Central Universities (HIT.NSRIF.201860), China Postdoctoral Science Foundation (No.2016M591535); their financial support is highly appreciated. 


\section{References}

[1] Wang XD, Liu JP. Behavior and design of slender square tubed-reinforced-concrete columns subjected to eccentric compression. Thin-Walled Structures 2017; 120: 153-160.

[2] Tomii M, Sakino K, Watanabe K, Xiao Y. Lateral Load Capacity of Reinforced Concrete Short Columns Confined by Steel Tube. In: Proceedings of the International Speciality Conference on Concrete Filled Steel Tubular Structures, Harbin, China, 1985; 19-26.

[3] Sakino K, Tomii M, Watanabe K. Sustaining Load Capacity of Plain Concrete Stub Columns Confined by Circular Steel Tube. In: Proceeding of the International Speciality Conference on Concrete Filled Steel Tubular Structures, Harbin, China, 1985; 112-8.

[4] Tomii M, Sakino K, Xiao Y, Watanabe K. Earthquake Resisting Hysteretic Behavior of Reinforced Concrete Short Columns Confined by Steel Tube. In: Proceedings of the International Speciality Conference on Concrete Filled Steel Tubular Structures, Harbin, China, 1985; 119-25.

[5] Aboutaha RS, Machado R. Seismic resistance of steel confined reinforced concrete (SCRC) columns. The Structural Design of Tall Buildings 1998; 7(3): 25160.

[6] Aboutaha RS, Machado RI. Seismic resistance of steel-tubed high-strength reinforced-concrete columns. Journal of Structural Engineering, ASCE 1999; 125(5): 485-94.

[7] Sun YP, Sakino K. Simplified design method for ultimate capacities of circularly confined high-strength concrete columns. ACI Special Publication 2000; 193: 571-85.

[8] Sun Y, Fukuhara T. Development of high seismic performance concrete frames. ACI Special Publication 2005; 228: 615-32.

[9] Han LH, Yao GH, Chen ZB, Yu Q. Experimental behaviours of steel tube confined concrete (STCC) columns. Steel and Composite Structures 2005; 5(6): 45984.

[10] Han LH, Qu H, Tao Z, Wang ZF. Experimental behaviour of thin-walled steel tube confined concrete column to RC beam joints under cyclic loading. Thin-Walled Structures 2009; 47: 847-57.

[11] Liu JP, Zhou XH. Behavior and strength of tubed RC stub columns under axial compression. Journal of Constructional Steel Research 2010; 66: 28-36.

[12]Zhou XH, Liu JP. Seismic behavior and shear strength of tubed RC short columns. Journal of Constructional Steel Research 2010; 66: 385-97.

[13] Liu JP, Wang X D, Zhang SM. Behavior of square tubed reinforced-concrete short columns subjected to eccentric compression. Thin-Walled Structures 2015; 91: 108-15.

[14] Wang XD, Liu JP, Zhang SM. Behavior of short circular tubed-reinforced-concrete columns subjected to eccentric compression. Engineering Structures 2015; 105: 77-86.

[15] Yu Q, Tao Z, Liu W, Chen ZB. Analysis and calculations of steel tube confined concrete (STCC) stub columns. Journal of Constructional Steel Research 2010; 66: 53-64.

[16] Liu F, Gardner L, Yang H. Post-fire behaviour of reinforced concrete stub columns confined by circular steel tubes. Journal of Constructional Steel Research 2014; 102: 82-103.

[17] Yang H, Liu F, Gardner L. Post-fire behaviour of slender reinforced concrete columns confined by circular steel tubes. Thin-Walled Structures 2015; 87: 12-29.

[18] Liu F, Yang H, Gardner L. Post-fire behaviour of eccentrically loaded reinforced concrete columns confined by circular steel tubes. Journal of Constructional Steel Research 2016; 122: 495-510.

[19] Abrams MS. Compressive strength of concrete at temperatures to $1600 \mathrm{~F}$. ACI Special Publication 1971; 25:33-58.

[20] Phan LT, Carino NJ. Reviewof mechanical properties of HSC at elevated temperature. Journal of Materials in Civil Engineering 1998; 10(1): 58-64.

[21] Hertz KD. Concrete strength for fire safety design. Magazine of Concrete Research 2005; 57(8): 445-453.

[22] Huo JS, Huang GW, Xiao Y. Effects of sustained axial load and cooling phase on post-fire behaviour of concrete-filled steel tubular stub columns. Journal of Constructional Steel Research 2009; 65: 1664-1676.

[23] ISO 834, Fire resistance tests-elements of building construction, International Organization for Standardization, Switzerland, 1975. 
[24]Liu F. Fire and post-fire behaviours of circular steel tube confined reinforced concrete columns. PhD disertation, Harbin Institute of Technology, 2014[in Chinese]

[25] Chabot M, Lie TT. Experimental studies on the fire resistance of hollow steel columns filled with bar-reinforced concrete. NRC-CNRC Internal Report 1992; No.628.

[26] Espinos A, Romero ML, Serra E, Hospitaler A. Fire resistance of circular and square slender concrete filled tubular columns subjected to large eccentricities. In: Proceedings of the 8th International Conference on Structures in Fire, Shanghai, China, 2014: 753-760.

[27] Han LH, Huo JS, Wang YC. Compressive and flexural behaviour of concrete filled steel tubes after exposure to standard fire. Journal of Constructional Steel Research 2005; 61: 882-901. 